\title{
AFSPC Innovation and Science and Technology Outreach to Industry and Academia
}

\author{
Merri J. Sanchez ${ }^{1}$ and Anthony N. Dills. ${ }^{2}$ \\ United States Air Force, Colorado Springs, CO 80914, USA \\ and \\ Faith Chandler ${ }^{3}$ \\ National Aeronautics and Space Administration, Washington, DC, 20546, USA
}

\begin{abstract}
The U.S. Air Force is taking a strategic approach to ensuring that we are at the cutting edge of science and technology. This includes fostering game-changing approaches and technologies that are balanced with operational needs. The security of the Nation requires a constant pursuit of science, technical agility, and a rapid adoption of innovation. This includes pursuits of game-changing technologies and domains that perhaps we cannot even imagine today. This paper highlights the Air Force Space Command (AFSPC) collaboration and outreach to other government agencies, military and national laboratories, industry, and academia on long term science and technology challenges. In particular we discuss the development of the AFSPC Long Term Science and Technology Challenges that include both space and cyberspace operations within a multi-domain environment and the subsequent Innovation Summits.
\end{abstract}

\section{Introduction}

$\mathrm{T}_{\mathrm{c}}^{\mathrm{h}}$ he U.S. Air Force Space Command (AFSPC) mission is to "Provide Resilient and Affordable Space and Cyberspace Capabilities for the Joint Force and Nation." The mission of the AFSPC Office of the Chief Scientist is to survey and assess cutting edge technologies and advise the Commander on all that have potential to drive operationally relevant space and cyberspace capabilities and enhance U.S. Air Force warfighting in the air, space and cyberspace domains.

To meet the Air Force needs in space and cyberspace 10-40 years in the future, emerging, breakthrough, disruptive and game-changing technologies that provide revolutionary improvements are required to stay ahead of adversary developments. As these technologies mature, they may be integrated into multi-domain, multi-mission portfolios ensuring we maintain assured persistent access to the space and cyberspace domains.

Evolutionary development and enhancement of current capabilities is no longer sufficient. Achieving success for each challenge requires innovative approaches and processes that identify and assess emerging science and technology (S\&T). The Office of the Chief Scientist developed the AFSPC Long Term Science and Technology Challenges process to identify technologies and guide S\&T activities that enable development and delivery of capabilities, ensuring our freedom of action in the space and cyberspace domains.

The Air Force Space Command (AFSPC) seeks ideas from the broadest possible base. We actively seek ideas from the private sector, laboratories, and academia. As the commercial presence in the space and cyber space domains expands, the commercial infrastructure should be leveraged. Yet we must ensure we maintain cyber security on our spacecraft, launch, and ground systems. We must also accept risks in the S\&T development process to reduce future risks borne by future programs. We must culturally evolve to allow "educationally successful" failed attempts during technology maturation. This will ultimately accelerate the development and use of new and innovative technologies that serve the warfighter.

${ }^{1}$ U.S. AFSPC Chief Scientist, U.S. AFSPC/ST, and AIAA Fellow.

${ }^{2}$ U.S. AFSPC Deputy Chief Scientist, U.S. AFSPC/DST, and AIAA Member.

${ }^{3}$ Director for Strategic Integration, Office of the Chief Technologist, NASA, and AIAA Member.

American Institute of Aeronautics and Astronautics 
This paper provides a brief review of current strategic motivators for the AFSPC Long Term S\&T Challenges. Following a general description of the challenges, we explain how we find solutions to our challenges through strategic inter-agency partnerships and activities.

\section{Background}

"The technological advantage that the Air Force has maintained since its inception was not predestined. It was the result of a strategic choice to explore and mature new technologies balanced with an understanding that military problems will never have final, or universal solutions. Only through a constant pursuit of science and a rapid adoption of innovation can the security of the nation be maintained" (U.S Air Force Strategic Master Plan, 2015). The Department of Defense Third Offset strategy is focused on the U.S. retaining technical advantage over our adversaries for the next 25 years using transformative technologies. ${ }^{1}$ Transformative technologies employed by the Air Force in the past include nuclear capabilities, precision guided munitions, and stealth. Today, the DoD Third Offset is focused on five key areas: autonomous "deep learning" machines and systems, human-machine collaboration, assisted-human operations, advanced human-machine teaming, and semi-autonomous "hardened" weapons. ${ }^{2}$ Our long term S\&T challenges are focused on identifying what is transformative in space and cyberspace.

"America's national security research and development system is structured to respond to military threats of last century...recognizing the crucial role of technology in the Second World War, post war America created an extensible infrastructure for national security science and technology." ${ }^{3}$ Put another way, our nation is fighting an information age war with industrial age technology. The innovation teams and solutions to our long term S\&T challenges will drive our approach to national security S\&T for the future.

The AFSPC science and technology process addresses the S\&T continuum and includes prototyping and experimentation, identification of near- and mid- term S\&T needs, and far-term S\&T challenges. Starting with a Rapid Prototyping event in 2016, AFSPC is committed to prototyping and experimentation that leads to rapid integration of technology. The S\&T needs development follows the process defined in Air Force Instruction AFI 61101 Management of Science and Technology for the Core Function Support Plans. This formal process uses capability collaboration teams to identify linkages between prioritized capability gaps and needs, capability concepts and material solutions, and enabling science and technologies, with typically a 5-10 year focus. The AFSPC Long Term S\&T Challenges process uses a collaborative team to think out of the box and toward the art of the possible of what technologies we can and should be maturing in the next 10-40 years for benefit to AFSPC but extensible to the AF and DoD in general. Our goal is to identify and drive technology developments that we are only starting to imagine and anticipate. This paper addresses the AFSPC Long Term S\&T Challenges.

Our S\&T challenges are driven by the National Space Policy (June 28, 2010) ${ }^{4}$ which directs innovation and collaboration to ensure our technical advantage. They are also guided by the Air Force Strategic Master Plan (SMP) (May 2015) ${ }^{5}$ which provides the strategic vectors of: deterrence; intelligence, surveillance, and reconnaissance (ISR); a full spectrum, high end force; a multi-domain approach to core missions; and use of game-changing technologies. The SMP directs that "we must pursue radical improvements in technology, that when combined with new approaches and organizational changes, expand or maintain asymmetric advantages over adversaries."

They also align with the following :

- Combatant Commander (COCOM) defined gaps and needs (Science and Technology Integrated Priority List);

- AFSPC Commander's Strategic Guidance, priorities and intent; ${ }^{4}$

- National Space Policy;

- DoD Space S\&T Strategy; ${ }^{6}$

- DoD Third Offset Strategy;

- OSTP National S\&T Council "21st Century Science, Technology, and Innovation Strategy for America's National Security"; and

- $\quad$ Space Enterprise Vision (developed jointly by AFSPC and the National Reconnaissance Office) ${ }^{7}$

The AFSPC Commander, General John Hyten, introduced the Space Enterprise Vision (SEV) during the 2016 Space Symposium and the next section summarizes this vision.

\footnotetext{
${ }^{4}$ www.afspc.af.mil/Home/Welcome
}

American Institute of Aeronautics and Astronautics 


\section{Space Enterprise Vision ${ }^{5}$}

Historically, the United States has enjoyed unimpeded freedom of action in the space domain to deliver effects our U.S. forces need to fight a modern war. However, the environment has changed. The U.S. space mission enterprise is always evolving to fight through and continue to deliver warfighting effects from today's contested space domain. Our adversaries understand the competitive advantage we derive from space and view our reliance on it as an exploitable vulnerability. The Space Enterprise Vision, or SEV, charts a course to a resilient space enterprise by 2030, able to deter aggression within the space domain and prevail in any high-end conflict that extends into space.

To reach this vision, space forces must operate as a single enterprise informed by threats and focused on meeting clearly defined warfighter essential requirements. We will harness government and commercial innovation to deliver lower-cost solutions faster, and leverage evolving science and technology advances sooner. We will present an experienced space force prepared to operate as an enterprise, and trained to defeat a thinking adversary.

There is also a culture change that needs to happen within the DoD. Consider today's acquisition processes and risk-adverse environment. It can take 10-15 years to field a new system. To avoid cost and schedule impacts, program managers must have the flexibility to make changes to systems when fielded. We must move to a more risk-tolerant, shorter, and flexible acquisition model in order to get and stay ahead of the advancing threat.

Our emphasis must also shift from simply maintaining continuity of space effects to improving resilience in response to emerging threats. Currently, our constellation replenishment decisions are informed by functional availability, a metric which evaluates performance-based engineering factors such as design life and component failure rate. This will be replaced by resilience capacity, which addresses adversary threats and a highly contested environment. Unfortunately, it is cost prohibitive to invest in resiliency satellite by satellite, so resiliency will be integrated into the design of the overall enterprise by employing concepts like disaggregation, proliferation of capability, maneuver, defensive operations, hardening, and human in-the-loop cyber protection.

This new vision provides both opportunities and challenges within the science and technology community. As mentioned, our partnerships with commercial industry and the civil space sector are key to harnessing the constant innovation and rapid technology advances occurring throughout the space industry. We will leverage the agile development and deployment processes employed by "New Space" companies as a model to increase flexibility and agility, reduce cost, improve technology insertion, and decrease program development and system design life-cycles to 3-5 years, accepting additional risk.

We will invest in concept development and experimentation to buy down risk prior to acquisition milestone B. These steps will speed constellation refresh rates and improve the availability of new technology on orbit making our systems more responsive and less vulnerable. We will evolve to a "freight train to space" launch model with more frequent, regularly scheduled launches along with a new approach to designing spacecraft to fit on standardized launchers with standardized interfaces for faster, more predictable access to space. There is much work to do in the near future.

\section{Long Term S\&T Challenges}

The AFSPC Long Term S\&T Challenges are cross-cutting across multiple domains and multiple missions. Solutions to these challenges are radical improvements, revolutionary, breakthrough, disruptive, and game-changing. They break paradigms. They give the U.S. asymmetric advantage. They create trusted and resilient combat effects through the next 30 years. They are pervasive, extensible, manufacturable, autonomous, reconfigurable, agile, and adaptable. They are agnostic to stove-pipe solutions. Where available, they leverage commercial capability. The challenges are living documents, being updated as we make advances or discover new challenges. They shape the future. The following eleven S\&T challenges were identified as the most critical to achieving our goals in both space and cyber over the next 10-35 years. It should be noted that the AFSPC Long Term S\&T Challenges will be available for public release in Summer 2016 and may be obtained from the AFSPC public website. ${ }^{4}$

AFSPC will release updated S\&T challenges in the Summer of 2016. Following the release of the challenges, AFSPC is sponsoring a two-phase Space and Cyberspace Innovation Summit. Industry, academia, and the laboratories are invited to attend Phase 1 where AFSPC will delve into further detail as to the types of technologies and applications we think are illustrative of the challenges. This will be the "crystal ball" to allow participants insight into the AFSPC challenges, and to determine if any of the challenges align with their S\&T capabilities. The crystal ball will help inform the participants on potential alignments they may want to make with their research and development. At the conclusion, the participants are encouraged to submit abstracts on their ideas of potential solutions that address any of

${ }^{5}$ Contributions from AF Space Command, Space Enterprise Vision Team, approved Distribution A statements. 2016.

American Institute of Aeronautics and Astronautics 
the challenges. After selecting the most applicable abstracts, participants will be invited to individually brief their ideas to a larger government audience with space and cyberspace equities.

\section{A. Space}

a. Enhanced multi-domain and multi-phenomenology Space Situational Awareness, Battlespace Awareness and ISR - Effective use of advancing sensor technologies to provide information of activities in the terrestrial, air, and space domains, including exploitation of multiple spectral regimes (infrared, ultraviolet, radio, optical, etc.), and the integration and human interface of the sensor-derived information.

b. New technologies applicable to extending space based capabilities - Space-based sustainment of existing operational satellites, resurrection of decommissioned satellites, on-board defense and resiliency factors, and selfhealing satellites.

c. Enhanced Space Access and Logistics - Use of evolved techniques to deploy space-based capabilities, such as multiple-payload boosters, resilient deployment, on-orbit servicing and construction (3-D, robotic, mini-factory, space station, etc.).

d. New concepts in space ground operations - Enterprise Ground Services, small-light-mobile emplaceable terminals, networking of high data rates, added resiliency, and defense of ground systems.

e. Dynamic new technologies applicable to all space systems - Autonomous and automated space systems with on-board sensors and warning technologies to defend against threats, micro-satellites and their communications methods, and smart mission disaggregation and aggregation.

\section{B. Cyber}

a. Trusted Autonomous Systems, Networks, and Applications - Advance technologies for autonomous, goalseeking network capabilities that access and exploit any available communication medium to preserve connectivity.

b. Human-Machine Interface Design and Biometrics - Advanced human-machine interface technologies for human performance augmentation and biometric based access to a multi-level security multi-domain Cyber Enterprise.

c. Advanced Data Protection Technologies - Resilient, scalable, and flexible low power data protection technologies that enable operators to seamlessly operate across classification domains with advanced user access methods.

\section{Cross-cutting}

a. Artificial Intelligence (AI)/Cognitive Electronic Warfare (CEW) - Technologies for systems to be controlled and defended by an inherent cognitive capability embedded in the system, reducing human involvement.

b. Artificial Intelligence (AI) - Technologies to advance Artificial Intelligence (AI) enabled, human decision augmentation.

c. Advanced Data Analytics - Technologies to synthesize and display voluminous multi-source data to predict, detect, inform, and augment the spectrum of cyberspace operations to allow comprehensive command and control and situational awareness.

This approach toward an innovative technology base will accelerate the introduction of new capabilities and provide the means for AFSPC to shape solutions that benefit the United States Air Force.

\section{Partnerships}

Partnerships with other services, government agencies, military and national laboratories are critical to ensure synergy and to leverage investments. AFSPC has developed critical S\&T partnerships at the working and strategic level with all of the government entities working space and cyberspace. These partnerships help us understand crossagency synergies and technical goals, as well as potential solutions and areas of collaboration, which are especially vital in these times of decreasing resources.

\section{A. Space S\&T Partnership Forum}

The Interagency Space S\&T Partnership Forum is a strategic forum established by the AFSPC Chief Scientist and the NASA Chief Technologist in 2015 to identify synergistic efforts and technologies between the multiple government organizations with space equities, explore ways to collaborate on investments, and facilitate cross-agency engagement. It is chaired by the AFSPC Chief Scientist, and has three lead agencies: Air Force, the National Aeronautics and Space Administration (NASA), and the National Reconnaissance Office (NRO). Additionally the 
Forum has participation from the Office of the Secretary of Defense Research and Engineering, Office of the Assistant Secretary of the Air Force for Acquisition (Science, Technology and Engineering) (SAF/AQR), Principal DoD Space Advisor (PDSA), Defense Advanced Research Projects Agency (DARPA), National Oceanic and Atmospheric Administration (NOAA), Space and Missiles Defense Center (SMDC), Air Force Research Laboratory (AFRL), and Naval Research Laboratory (NRL). Since the Forum membership consists of agency and organization chief scientists and technology officers, the Forum naturally provides a multiagency voice on government S\&T to advise senior leaders on synergies, collaborations, and the state of the art for space technologies.

The Forum has a near term goal of actively working to cross-walk AF-NASA-NRO roadmaps to identify opportunities for synergies and collaboration in technology investments. Additionally, the Forum will develop a strategy for a joint roadmap that focuses on mutually beneficial long term goals. The S\&T Partnership Forum is accomplishing this through personnel exchange (e.g., AFRL detail to NASA Headquarters, Office of the Chief Technologist), technology evaluation collaborations (e.g., High Power Solar Electric Propulsion and Upper-Stage Rocket technology), and multiple Technical Interchange Meetings (TIMs).

For example, to identify pervasive technologies that would provide the first opportunity for a detailed cross-walk, NASA hosted a TIM where the S\&T Partnership Forum met, and generated 16 topics for consideration. These were prioritized within each agency based on their own criteria, and then integrated to identify the top topics for future collaborative work to provide mutual benefit. These included small satellite technology development, big data analytics, in-space assembly, cyber security, and assured access to space.

To pilot the development of an integrated roadmap, the S\&T Partnership Forum selected small satellite technology as the first collaborative area, with a focus on developing miniaturized sensing capabilities for cubesat and small-sat platforms. Miniaturized sensors bring a new way to do a mission, overcome previous barriers, and can be a resilient data source. Small spacecraft are adaptable, tactically responsive, potential mission gap fillers, and provide reconfigurable constellations. The Government recognizes that small satellites are a viable and relevant industry niche that can add value to government systems.

In July 2016, NASA and AFSPC hosted a government TIM to ascertain current investments in the area of small miniaturized sensors including: optical, energetic charged particles electromagnetic, local spacecraft environment, and sensor web technologies, among others. The TIM identified key sensor technologies with the most cross-agency impact, and started developing integrated technology Venn diagrams for the investments mentioned. Later, the organizations will work to identify key sensor technologies with most cross-agency Return on Investment, develop a technology roadmap for miniaturized sensor technology, and document federal government activities. A natural product of this activity should yield identification of federal technology needs and gaps and a unified vision for future small satellite work. Progress in this activity was briefed at the "The Future of Small Space-Based Systems" technology workshop on August 11, 2016 at the Space Dynamics Laboratory facility in Logan, Utah. The S\&T Partnership Forum will report their progress at the senior leader AF-NASA-NRO Space Summit in Washington DC in the fall of 2016. Applying feedback from the senior leadership, the S\&T Partnership Forum will continue to identify key sensor technologies with most cross-agency Return on Investment, develop a miniaturized satellite technology roadmap, and document federal government activities. The Forum's goal is to conduct a pilot project to identify federal technology needs and gaps, and generate a unified vision for future small satellite work, and develop a shared "component library" with lessons learned and reliability information.

Using the model set forth with the small satellite technology focus, the Interagency S\&T Partnership will expand their focus into the other goals mentioned earlier. Overall, these activities will strengthen National technology development capability as well find solutions to the AFSPC Long Term S\&T Challenges.

\section{B. Other Partnership Activities}

In addition to the AF-NASA-NRO led partnership forum, the Office of Science and Technology Policy (OSTP) is beginning a new "whole of government" small satellite initiative to obtain overall level of interest across government departments and agencies and to identify potential steps forward for the Executive Branch. This initiative builds upon numerous other government initiatives and strategies, such as Secretary Carter's Defense Innovation Unit Experimental (DIUx) and the Third Offset Strategy. As such, the Interagency S\&T Partnership Forum small satellite technology activities align well to the OSTP initiative and should provide meaningful technical input from interagency partners. Such inputs could be a mechanism to balance risk tolerance and reliability; U.S. standards for locating and identifying small satellites for multi-national space situational awareness; and technical reports on the trends in small satellite technology research and development $(R \& D)$ fabrication, integration, and testing.

American Institute of Aeronautics and Astronautics 


\section{Conclusion}

The cornerstone challenges and the approach to accelerate the introduction of paradigm-changing capabilities through technical maturation and experimentation remain our focus now and into the future. We identified key technology areas that address pervasive and game-changing challenges across government space and cyberspace. The AF, NASA, and NRO are aggressively collaborating to find enterprise level, synergistic S\&T solutions to benefit the Nation. Together, everyone in the space industry must ensure that we all maintain cyber security on our spacecraft, launch, and ground systems. We must also accept risks in the S\&T development process to reduce future risks borne by future programs and we must culturally evolve to allow "educationally successful" failed attempts at technology maturation. This will ultimately accelerate the introduction of new and innovative technologies to better serve the warfighter. Finally, we will continue cross-agency collaborations to gain synergy in S\&T development.

\section{References}

${ }^{1}$ Pomerleau, Mark., "DOD's Third Offset Strategy: What man and machine can do together." Defense Systems [Online database], URL: https://defensesystems.com/articles/2016/05/04/dod-work-on-third-offset-strategy.aspx, [cited 4 May 2016].

${ }^{2}$ Mehta, Aaron., "Work Outlines Key Steps in Third Offset Tech Development." Defense News [Online database], URL: http://www.defensenews.com/story/defense/innovation/2015/12/14/work-third-offset-techdevelopment-pentagon-russia/77283732/, [cited 14 December 2015].

${ }^{36}$ "A $21^{\text {st }}$ Century Science, Technology, and Innovation Strategy for America's National Security." The Whitehouse. [Online database], URL: https://www.whitehouse.gov/sites/default/files/microsites/ostp/NSTC/ national_security_s_and_t_strategy.pdf, [cited May 2016].

"National Space Policy of the United States of Americs." The Whitehouse. [Online database], URL: https://www.whitehouse.gov/sites/default/files/national space policy 6-28-10.pdf, [cited 28 June 2010].

${ }^{5}$ James, D. L., and Welsh, M. A. III., "USAF Strategic Master Plan." US Air Force. [Online database], URL: http://www.af.mil/Portals/1/documents/Force\%20Management/Strategic_Master_Plan.pdfs, [cited May 2015].

6“Department of Defense Space Science and Technology Strategy 2015." Defense Innovation Marketplace. [Online database], URL: http://www.defenseinnovationmarketplace.mil/resources/ 2015 DoD Space ST Strategy FINAL, [cited 2015].

${ }^{7}$ AFSPC Public Affairs. "AFSPC Commander Announces Space Enterprise Vision.” Air Force Space Command. [Online database], URL: http://www.afspc.af.mil/News/Article-Display/Article/730817/afspccommander-announces-space-enterprise-vision, [cited 11 April 2016]. 